\title{
A novel technique for the treatment of impacted pancreatic stones after pancreatoduodenectomy using transanastomotic fluoroscopic-guided electrohydraulic lithotripsy
}
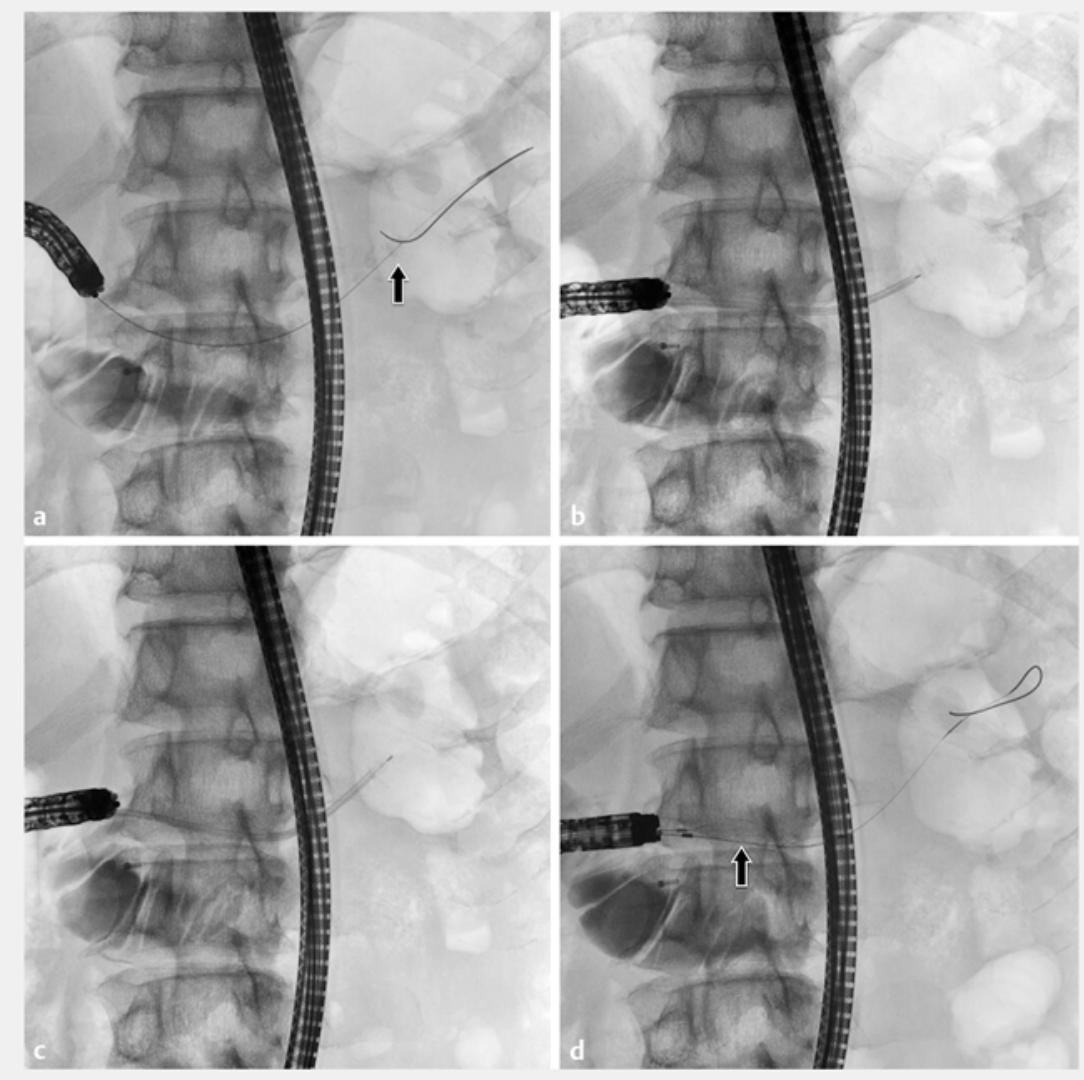

- Fig. 1 Fluoroscopic images in a 66-year-old man with obstructing pancreatic duct stones after pancreatoduodenectomy showing: a impacted radiopaque pancreatic stones in the main pancreatic duct (arrow); b an electrohydraulic lithotripsy (EHL) probe inserted through a sheath, with its tip contacting the stones; $\mathbf{c}$ the EHL probe passing through the stones after $\mathrm{EHL}$; $\mathbf{d}$ the last stone fragment being removed with a basket catheter (arrow).

Nowadays the role of endoscopic intervention is becoming more important in patients with obstructive pancreatitis. Although a recent study reported that $90 \%$ of patients with obstructing pancreatic stones achieved pancreatic ductal clearance using digital single-operator pancreatoscopy (D-SOP) with electrohydraulic lithotripsy (EHL) or laser lithotripsy [1], endoscopic treatment of obstructive pancreatic stones is still challenging in patients with surgically altered anatomy. Here, we report a novel technique for the treatment of impacted pancreatic stones after pancreatoduodenectomy without using D-SOP.

A 66-year-old man, who underwent pancreatoduodenectomy with Child's reconstruction 23 years earlier for annular pancreas, was referred for the treatment of obstructive pancreatitis caused by pancreatic stones. Endoscopic removal of the pancreatic stones was attempted using a short-type single-balloon enteroscope (SIF-H290S; Olympus Medical Systems, Tokyo, Japan) with a 3.2-mm

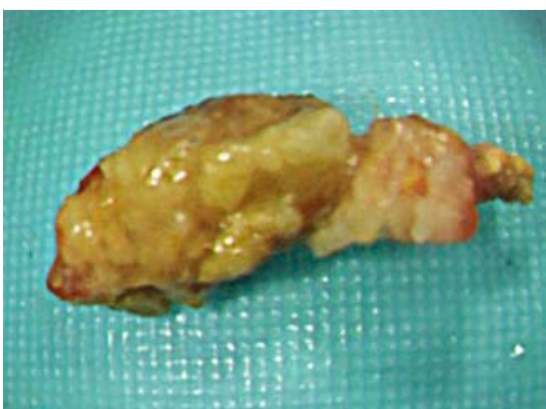

Fig. 2 A stone fragment removed from the main pancreatic duct.

working channel. Endoscopic retrograde pancreatography was performed via a stenotic pancreaticojejunal anastomosis to confirm impacted radiopaque pancreatic stones in the main pancreatic duct. Although a 0.025-inch guidewire was able to be advanced beyond the stones, neither a tapered catheter with a tip diameter of 3.3 Fr (SHOREN; Kaneka Medix, Osaka, Japan) nor a 4-mm balloon catheter with a well-tapered tip of 2.75 Fr (REN; Kaneka Medix) was able to pass through the stones.

We therefore opted to treat the stones with fluoroscopic-guided EHL. First, the pancreaticojejunal anastomosis was dilated with an 8-mm balloon catheter (ZARA; Century Medical, Tokyo, Japan). Next, a sheath, which was made by cutting the tip of a 7-Fr biliary dilation catheter (Soehendra; Cook Medical Japan, Tokyo, Japan), was advanced over the guidewire to contact the stones. Then, after withdrawing the guidewire, an $\mathrm{EHL}$ probe was inserted through the sheath. Finally, the stones were fragmented with $\mathrm{EHL}$ and removed with a wire-guided basket catheter (basket catheter NT; Zeon Medical, Tokyo, Japan) (\$ Fig.1, > Fig. 2, > Video 1).

Endoscopy_UCTN_Code_TTT_1AR_2AI 


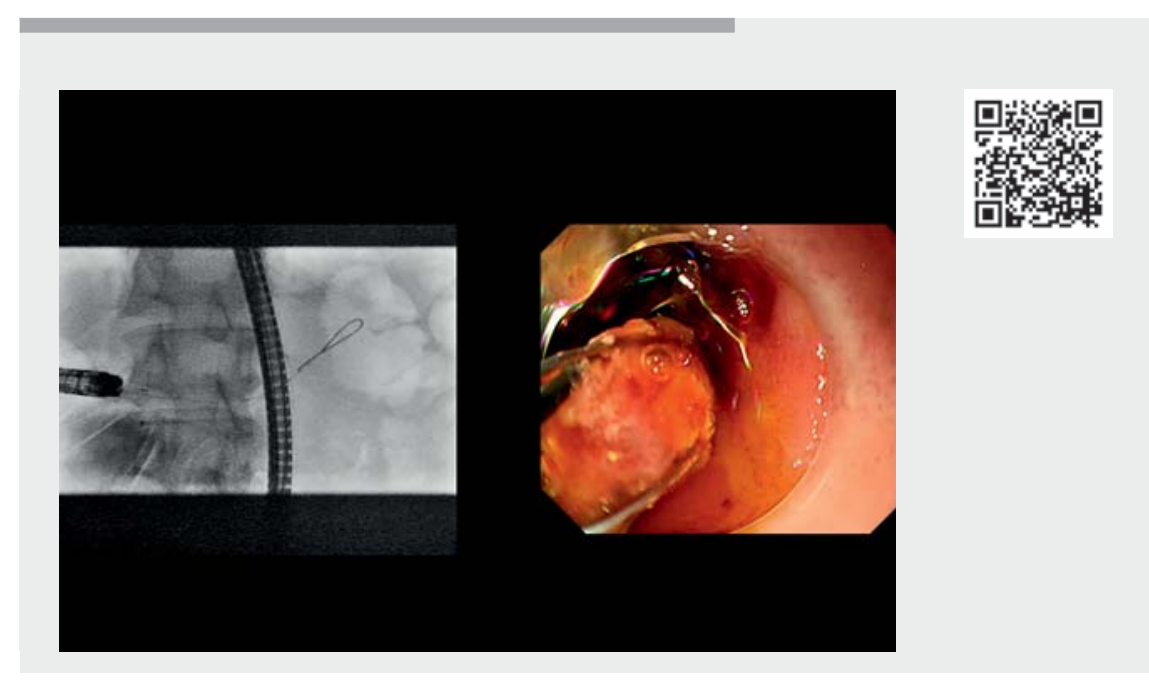

$\checkmark$ Video 1 Endoscopic treatment of impacted pancreatic stones after pancreatoduodenectomy using transanastomotic fluoroscopic-guided electrohydraulic lithotripsy.

\section{Competing interests}

The authors declare that they have no conflict of interest.

The authors

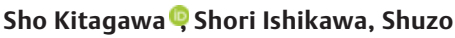

Monden

Department of Gastroenterology, Sapporo Kosei General Hospital, Sapporo, Japan

\section{Reference}

\section{Bibliography}

Endoscopy 2022; 54: E617-E618

DOI 10.1055/a-1722-2681

ISSN 0013-726X

published online 26.1.2022

(c) 2022. Thieme. All rights reserved.

Georg Thieme Verlag KG, Rüdigerstraße 14,

70469 Stuttgart, Germany

\section{ENDOSCOPY E-VIDEOS \\ https://eref.thieme.de/e-videos}

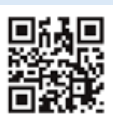

Endoscopy E-Videos is an open access online section, reporting on interesting cases and new techniques in gastroenterological endoscopy. All papers include a high quality video and all contributions are freely accessible online. Processing charges apply (currently EUR 375), discounts and wavers acc. to HINARI are available.

This section has its own submission website at

https://mc.manuscriptcentral.com/e-videos
[1] Brewer Gutierrez OI, Raijman I, Shah RJ et al. Safety and efficacy of digital single-operator pancreatoscopy for obstructing pancreatic ductal stones. Endosc Int Open 2019; 7: E896-E903

\section{Sho Kitagawa, MD}

Kosei General Hospital, Kita 3 Higashi 8,

Chuo-ku, Sapporo 060-0033, Japan

bossa0405@yahoo.co.jp 